Supporting Information for:

\title{
Localization of Spiropyran Activation
}

Martha E. Grady, ${ }^{*}$ Cassandra M. Birrenkott,${ }^{2}$ Preston A. May, ${ }^{\$ 3}$ Scott $R$. White,$\dagger^{4,6}$ Jeffrey S. Moore, ${ }^{3,6}$ Nancy R. Sottos ${ }^{5,6}$

${ }^{1}$ Department of Mechanical Engineering, University of Kentucky, 506 Administration Drive, Lexington, KY, 40506 USA

${ }^{2}$ Department of Mechanical Engineering, South Dakota School of Mines and Technology, 501 E.

Saint Joseph St. Rapid City, SD 57701 USA

${ }^{3}$ Department of Chemistry, University of Illinois at Urbana-Champaign, 505 S. Mathews Avenue, Urbana, IL, 61801, USA

${ }^{4}$ Department of Aerospace Engineering, University of Illinois at Urbana- Champaign, 104 S. Wright Street, Urbana, IL, 61801, USA

${ }^{5}$ Department of Materials Science and Engineering, University of Illinois at Urbana-Champaign, 1304 W. Green Street, Urbana, IL, 61801, USA

${ }^{6}$ Beckman Institute for Advanced Science and Technology, University of Illinois at UrbanaChampaign, 405 N. Mathews Avenue, Urbana, IL, 61801, USA

*Corresponding Author E-mail Address: m.grady@uky.edu

\section{Contents}

Number of Pages: 6

Number of Schemes: 5

\section{Table of Contents}

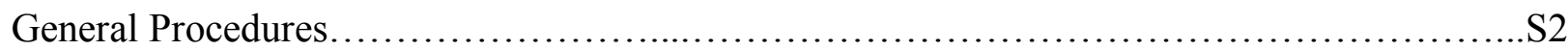

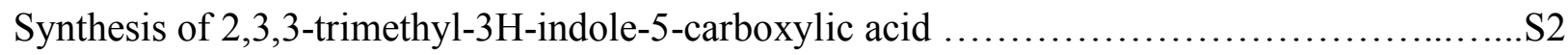

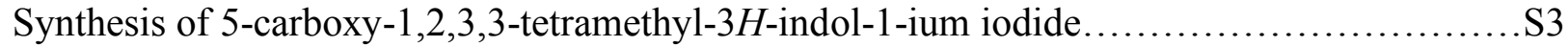

Synthesis of 8-hydroxy-1',3',3'-trimethyl-6-nitrospiro[chromene-2,2'-indoline]-5'-carboxylic

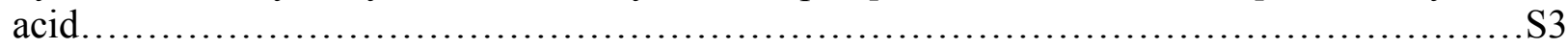

Synthesis of 8-(methacryloyloxy)-1',3',3'-trimethyl-6-nitrospiro[chromene-2,2'-indoline]-5'-

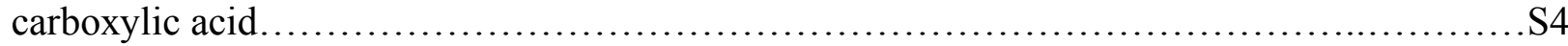

Synthesis of 8-methoxy-1',3',3'-trimethyl-6-nitrospiro[chromene-2,2'-indoline]-5'-carboxylic

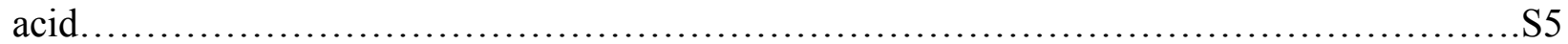

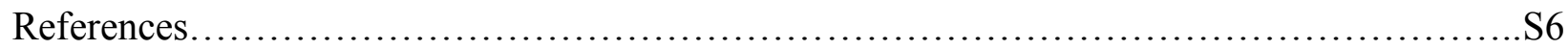




\section{General Procedures}

Unless otherwise stated, all starting materials were obtained from commercial suppliers and used without purification. Dry dichloromethane and THF were obtained from an Anhydrous Engineering Solvent Delivery System (SDS) equipped with activated alumina columns. All reactions were performed under a N2 atmosphere unless otherwise specified.

Flash column chromatography was conducted with silica gel 60 (230-400 mesh) from Silicycle. 1H and 13C NMR spectra were obtained using either a Varian 400 or $500 \mathrm{MHz}$ spectrometer in the VOICE NMR laboratory at the University of Illinois; the residual solvent protons were used to reference the chemical shift. Coupling constants $(J)$ are reported in Hertz $(\mathrm{Hz})$, and splitting patterns are designated as s (singlet), d (doublet), $\mathrm{t}$ (triplet), q (quartet), $\mathrm{m}$ (multiplet), and br (broad). Mass spectra were obtained through the Mass Spectrometry Facility, SCS, University of Illinois. Melting points were obtained using a differential scanning calorimetry was performed on a Mettler-Toledo DSC 821e, calibrated by indium, octane and zinc standards with a heating rate was $10{ }^{\circ} \mathrm{C} \cdot \mathrm{min}-1$.

\section{Synthesis of 2,3,3-trimethyl-3H-indole-5-carboxylic acid ${ }^{1}$}
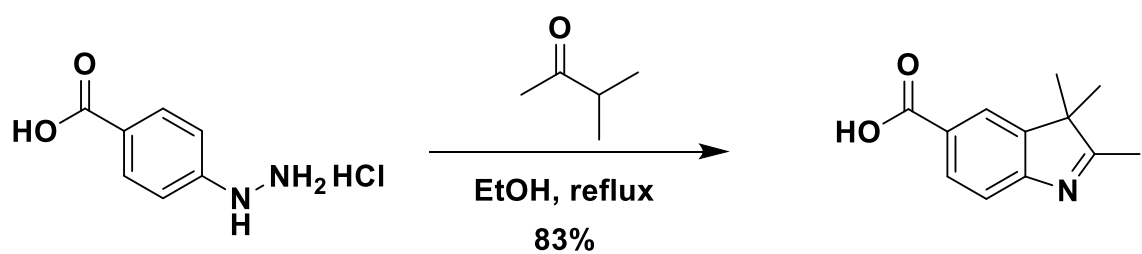

Scheme S1. Synthesis of 2,3,3-trimethyl-3H-indole-5-carboxylic acid.

4-benzoic acid hydrazine hydrochloride (1.00 g, $5.30 \mathrm{mmol}, 1 \mathrm{equiv})$ and methyl isopropyl ketone $(0.568 \mathrm{~mL}, 5.30 \mathrm{mmol}, 1$ equiv) were dissolved in $40 \mathrm{~mL}$ absolute $\mathrm{EtOH}$ and heated to reflux using a reflux condenser under $\mathrm{N}_{2}$ pressure. After refluxing for $5 \mathrm{~h}$, the solution was concentrated in vacuo. The material was redissolved in $\mathrm{CH}_{2} \mathrm{Cl}_{2}$, filtered through celite and evaporated to dryness. The product was used in the next reaction without any further purification. Orange solid: $896 \mathrm{mg}(83 \%)$.

${ }^{1} \mathrm{H}$ NMR (400 MHz, d6-DMSO ): $\boldsymbol{\delta} 12.83$ (s, 1H,); 7.99 (d, J=1.7 Hz), 7.91 (dd, J = 1.7 Hz, J = $8.2 \mathrm{~Hz}, 1 \mathrm{H}), 7.50(\mathrm{~d}, \mathrm{~J}=8.2 \mathrm{~Hz}, 1 \mathrm{H}), 2.25(\mathrm{~s}, 3 \mathrm{H}), 1.28(\mathrm{~s}, 6 \mathrm{H})$. 
${ }^{13} \mathrm{C}\left\{{ }^{1} \mathrm{H}\right\} \operatorname{NMR}\left(125 \mathrm{MHz}, \mathrm{CDCl}_{3}\right) \boldsymbol{\delta} 192.9,171.0,156.7,145.5,130.9,128.4,123.4,119.7,54.1$, 23.0, 15.6.

LRMS-ESI $(m / z):[\mathrm{M}+\mathrm{H}]+$ calcd for $\mathrm{C}_{12} \mathrm{H}_{14} \mathrm{NO}_{2}$, 204.10; found, 204.0.

MP: $192-194{ }^{\circ} \mathrm{C}(\mathrm{DSC})$.

\section{Synthesis of 5-carboxy-1,2,3,3-tetramethyl-3H-indol-1-ium iodide ${ }^{1}$}

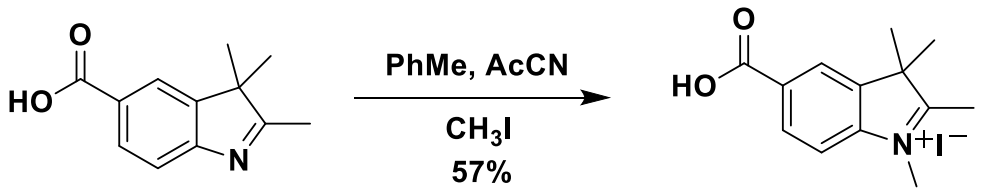

Scheme S2. Synthesis of 5-carboxy-1,2,3,3-tetramethyl-3H-indol-1-ium iodide.

The indole (508 mg, $42.49 \mathrm{mmol}, 1$ equiv) was added to $4 \mathrm{~mL}$ of toluene and $2 \mathrm{~mL}$ of acetonitrile. Methyl iodide (778 $\mu \mathrm{L}, 12.45 \mathrm{mmol}, 5$ equiv) was added and heated to $75^{\circ} \mathrm{C}$ using a reflux condenser under $\mathrm{N}_{2}$ pressure. After $24 \mathrm{~h}$, the solution was filtered and washed with EtOH and hexanes to give a tan solid: (488 $\mathrm{mg}, 57 \%$ ).

${ }^{1} \mathrm{H}$ NMR (400 MHz, d 6 -DMSO): $\delta 8.38$ (s, 1H), 8.19 (d, $\left.J=8.4 \mathrm{~Hz}\right), 8.02$ (d, $\left.J=8.4 \mathrm{~Hz}\right), 3.99$ $(\mathrm{s}, 3 \mathrm{H}), 2.80(\mathrm{~s}, 3 \mathrm{H}), 1.56(\mathrm{~s}, 6 \mathrm{H})$

${ }^{13} \mathrm{C}$ NMR $[100 \mathrm{MHz}, \mathrm{CD} 3 \mathrm{CN} / \mathrm{CD} 3 \mathrm{OD}(5: 1, \mathrm{v} / \mathrm{v})]$ : $\boldsymbol{\delta} 167.5,143.2,133.5,132.2,125.5,116.4$, $56.0,36.0,22.4$.

LRMS-ESI-TOF $(m / z)$ : [M]+ calcd for $\mathrm{C}_{13} \mathrm{H}_{16} \mathrm{NO}_{2}, 218.12$; found, 218.1.

Synthesis of 8-hydroxy-1',3',3'-trimethyl-6-nitrospiro[chromene-2,2'-indoline]-5'-carboxylic acid

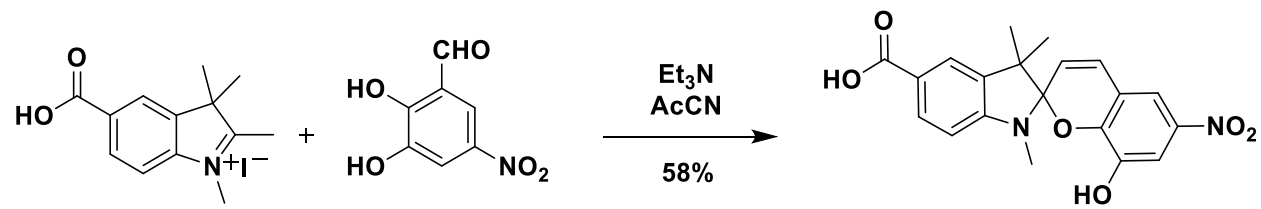

Scheme S3. Synthesis of 8-hydroxy-1',3',3'-trimethyl-6-nitrospiro[chromene-2,2'-indoline]-5'carboxylic acid. 
The indole salt (469 mg, $1.36 \mathrm{mmol}, 1$ equiv), 2,3-dihydroxy-5-nitrobenzaldehyde ${ }^{2}$ (249 mg, $1.36 \mathrm{mmol}, 1$ equiv), and triethylamine $(0.379 \mathrm{~mL}, 2.72 \mathrm{mmol}, 2$ equiv) were dissolved in $13 \mathrm{~mL}$ acetonitrile and heated to reflux at $100{ }^{\circ} \mathrm{C}$. After $5 \mathrm{~h}$, the solution was removed from heat, filtered, washed with $\mathrm{AcCN}$, and the precipitate dried under high vacuum to give a black solid: (301 mg, $58 \%)$.

${ }^{1} \mathrm{H}$ NMR (400 MHz, d6-DMSO): $\boldsymbol{\delta} 10.31(\mathrm{~s}, 1 \mathrm{H}), 7.81(\mathrm{dd}, \mathrm{J}=1.7, \mathrm{~J}=8.2,1 \mathrm{H}), 7.74(\mathrm{~d}, \mathrm{~J}=2.8$, 1H), $7.65(\mathrm{~d}, \mathrm{~J}=1.7 \mathrm{~Hz}, 1 \mathrm{H}), 7.56(\mathrm{~d}, \mathrm{~J}=2.8 \mathrm{~Hz}, 1 \mathrm{H}), 7.17(\mathrm{~d}, \mathrm{~J}=10.4 \mathrm{~Hz}, 1 \mathrm{H}), 6.69$ (d, J = 8.2 $\mathrm{Hz}, 1 \mathrm{H}), 5.96$ (d, J = 10.4 Hz, 1H), 3.81 (br, 1H), 2.77 (s, 3H), 1.24 (s, 3H), 1.19 (s, 3H). LRMS-ESI (m/z): [M]- calcd for $\mathrm{C}_{20} \mathrm{H}_{17} \mathrm{~N}_{2} \mathrm{O}_{6}, 381.11$; found, 381.1 .

\section{Synthesis of 8-(methacryloyloxy)-1',3',3'-trimethyl-6-nitrospiro[chromene-2,2'-indoline]-5'- carboxylic acid}

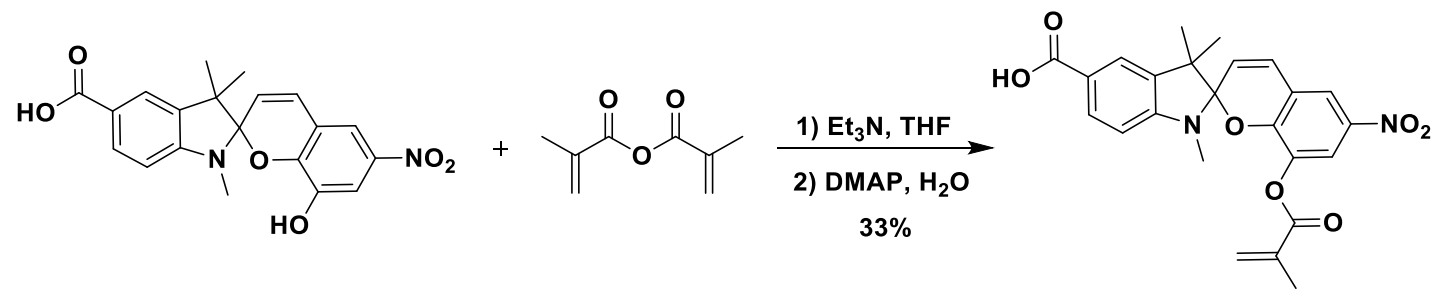

Scheme S4. Synthesis of 8-(methacryloyloxy)-1',3',3'-trimethyl-6-nitrospiro[chromene-2,2'indoline]-5'-carboxylic acid.

The spiropyran (548 mg, $1.43 \mathrm{mmol}, 1$ equiv) was partially dissolved in $15.3 \mathrm{~mL}$ of THF. Triethylamine ( $420 \mu \mathrm{L}, 3.01 \mathrm{mmol}, 2.1$ equiv) was added followed by methacrylic anhydride ( 858 $\mu \mathrm{L}, 5.73 \mathrm{mmol}, 4$ equiv) and the solution was allowed to stir at $\mathrm{rt}$ for $24 \mathrm{~h}$. Next, to hydrolyze the excess methacrylic anhydride and the anhydride formed on the spiropyran, DMAP (367 mg, 2.87 mmol, 2 equiv) was added and allowed to dissolved followed by the addition of $4 \mathrm{~mL}$ of $\mathrm{DI}_{2} \mathrm{O}$. The reaction mixture was allowed to stir at $\mathrm{rt}$ for another $24 \mathrm{~h}$. Next, the reaction mixture was added to $150 \mathrm{~mL}$ of $\mathrm{CH}_{2} \mathrm{Cl}_{2}$ and washed with aqueous $\mathrm{NaHSO}_{4}(2 \times 150 \mathrm{~mL})$, then washed with brine $(1 \times 150 \mathrm{~mL})$. The organic layer was dried with $\mathrm{Na}_{2} \mathrm{SO}_{4}$, filtered and evaporated to dryness. The product was purified by column chromatography eluting with $0.5 \% \mathrm{MeOH}$ in $\mathrm{CH}_{2} \mathrm{Cl}_{2}$ to give a light green solid: $216 \mathrm{mg}(33 \%)$. 
${ }^{1} \mathrm{H}$ NMR (500 MHz, d d -DMSO): $\boldsymbol{\delta} 12.3(\mathrm{~s}, 1 \mathrm{H}), 8.24(\mathrm{~d}, \mathrm{~J}=2.7 \mathrm{~Hz}, 1 \mathrm{H}), 8.02(\mathrm{~d}, \mathrm{~J}=2.7 \mathrm{~Hz}, 1 \mathrm{H})$, $7.79(\mathrm{dd}, \mathrm{J}=1.7 \mathrm{~Hz}, \mathrm{~J}=8.2 \mathrm{~Hz}, 1 \mathrm{H}), 7.63(\mathrm{~d}, \mathrm{~J}=1.7 \mathrm{~Hz}, 1 \mathrm{H}), 7.34$ (d, J = 10.4 Hz, 1H), 6.65 (d, $\mathrm{J}=8.2 \mathrm{~Hz}, 1 \mathrm{H}), 6.11(\mathrm{~d}, \mathrm{~J}=10.4 \mathrm{~Hz}, 1 \mathrm{H}), 5.83(\mathrm{~m}, 1 \mathrm{H}), 5.51(\mathrm{~m}, 1 \mathrm{H}), 2.65(\mathrm{~s}, 3 \mathrm{H}), 1.54(\mathrm{~s}, 3 \mathrm{H})$, $1.21(\mathrm{~s}, 3 \mathrm{H}), 1.15(\mathrm{~s}, 3 \mathrm{H})$.

LRMS-ESI $(m / z)$ : [M - H] $]^{-}$calcd for $\mathrm{C}_{24} \mathrm{H}_{21} \mathrm{~N}_{2} \mathrm{O}_{7}, 449.14$; found, 449.5 .

Synthesis of $\quad 8$-methoxy-1',3',3'-trimethyl-6-nitrospiro[chromene-2,2'-indoline]-5'carboxylic acid ${ }^{1}$

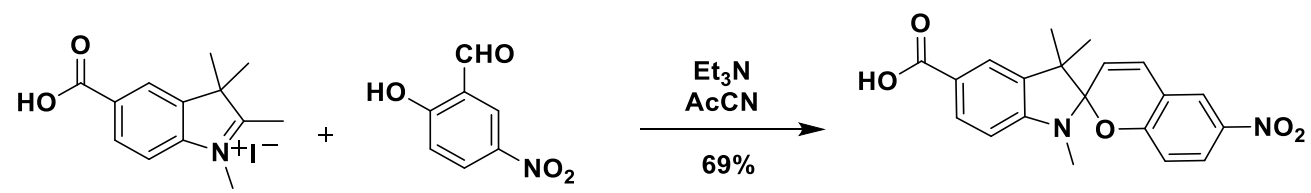

Scheme S5. Synthesis of 8-methoxy-1',3',3'-trimethyl-6-nitrospiro[chromene-2,2'-indoline]-5'carboxylic acid.

Indole salt (503 mg, $1.46 \mathrm{mmol}, 1$ equiv ), 2-hydroxy-5-nitrobenzaldehyde (244 mg, 1.46 mmol, 1 equiv), and triethylamine (203 $\mu \mathrm{L}, 1.46 \mathrm{mmol}, 1$ equiv) were dissolved in $15 \mathrm{~mL}$ acetonitrile and heated to reflux. After 24 hours, the solution was removed from heat, filtered, washed with $\mathrm{AcCN}$ and $\mathrm{EtOH}$, and the precipitate was dried under high vacuum to yield the product as a light green solid: (371 $\mathrm{mg}, 69 \%)$.

${ }^{1} \mathrm{H}$ NMR (400 MHz, d6-DMSO): $\boldsymbol{\delta} 12.39$ (s, 1H), 8.25 (d, J = 2.8 Hz, 1H), 8.02 (dd, J = 2.8 Hz, J $=9.0 \mathrm{~Hz}, 1 \mathrm{H}), 7.81(\mathrm{dd}, \mathrm{J}=1.8, \mathrm{~J}=8.2 \mathrm{~Hz}, 1 \mathrm{H}), 7.67(\mathrm{~d}, \mathrm{~J}=1.8 \mathrm{~Hz}, 1 \mathrm{H}), 7.26(\mathrm{~d}, \mathrm{~J}=10.4 \mathrm{~Hz}$, 1H), $6.92(\mathrm{~d}, \mathrm{~J}=9.0 \mathrm{~Hz}, 1 \mathrm{H}), 6.70(\mathrm{~d}, \mathrm{~J}=8.2 \mathrm{~Hz}), 6.02(\mathrm{~d}, \mathrm{~J}=10.4 \mathrm{~Hz}), 2.76(\mathrm{~s}, 3 \mathrm{H}), 1.24(\mathrm{~s}, 3 \mathrm{H})$, $1.13(\mathrm{~s}, 3 \mathrm{H})$.

${ }^{13} \mathrm{C}\left\{{ }^{1} \mathrm{H}\right\}$ NMR (125 MHz, $\left.\mathrm{CDCl}_{3}\right): \boldsymbol{\delta} 167.3,158.9,151.2,140.7,135.9,130.8,128.5,125.8,122.9$, 122.8, 121.6, 120.9, 118.8, 115.4, 106.2, 105.9, 51.5, 28.4, 25.5, 19.5.

LRMS-FD $(m / z)$ : [M]+ calcd for $\mathrm{C}_{20} \mathrm{H}_{18} \mathrm{~N}_{2} \mathrm{O}_{5}, 366.12$; found, 366.1 .

M.P. $163-165^{\circ} \mathrm{C}(\mathrm{DSC})$. 


\section{References}

(S1) Tomasulo, M.; Kaanumal, S. L.; Sortino, S.; Raymo, F. M., Synthesis and Properties of Benzophenone-Spiropyran and Napthalene-Spiropyran Conjugates. J. Org. Chem. 2007, 72, 595-605.

(S2) Davis, D. A.; Hamilton, A.; Yang, J.; Cremar, L. D.; Van Gough,D.; Potisek, S. L.; Ong, M. T.; Braun, P. V.; Martínez, T. J.; White, S.R.; Moore, J. S.; Sottos, N. R. Nature 2009, $459,68-72$. 